\title{
Esterification using a liquid lipase to remove residual free fatty acids in biodiesel
}

\author{
Hansen, R. B.; Agerbaek, M. A.; Nielsen, P. M.; Rancke-Madsen, A.; Woodley, J. M.
}

Published in:

Process Biochemistry

Link to article, DOI:

10.1016/j.procbio.2020.06.005

Publication date:

2020

Document Version

Peer reviewed version

Link back to DTU Orbit

Citation (APA):

Hansen, R. B., Agerbaek, M. A., Nielsen, P. M., Rancke-Madsen, A., \& Woodley, J. M. (2020). Esterification using a liquid lipase to remove residual free fatty acids in biodiesel. Process Biochemistry, 97, 213-221. https://doi.org/10.1016/j.procbio.2020.06.005

\section{General rights}

Copyright and moral rights for the publications made accessible in the public portal are retained by the authors and/or other copyright owners and it is a condition of accessing publications that users recognise and abide by the legal requirements associated with these rights.

- Users may download and print one copy of any publication from the public portal for the purpose of private study or research.

- You may not further distribute the material or use it for any profit-making activity or commercial gain

- You may freely distribute the URL identifying the publication in the public portal 
1 Esterification using a liquid lipase to remove residual free fatty acids in biodiesel

2

3 R.B. Hansen'), M.A. Agerbaek ${ }^{1)}$, P.M. Nielsen²), A. Rancke-Madsen ${ }^{2)}$ and J.M. Woodley ${ }^{1)}$

4 1) Department of Chemical and Biochemical Engineering, Technical University of Denmark, 5 Soltofts Plads, Building 227, 2800 Kgs. Lyngby, Denmark

6 2) Novozymes A/S, Vegetable oil processing R\&D, Krogshojvej 36, 2800 Lyngby, Denmark

7

8 Abstract

9 Lately, the price of liquid formulated lipase enzymes, usable in biodiesel production, has

10 been significantly reduced. This enables one-time use of these enzymes for

11 transesterification, and the process is used industrially. However, the process suffers a

12 drawback by leaving 2-3\% free fatty acids in the crude biodiesel, which reduces the

13 profitability. This article discusses a novel enzymatic FFA esterification reaction utilizing

14 liquid lipase $B$ from Candida antarctica (CALB) along with glycerol at low water

15 concentrations to eliminate the residual FFA. The reaction setup was found able to reduce

16 the free fatty acid concentration to within biodiesel specifications of $<0.25 \mathrm{wt}$. $\%$ FFA.

17 Additionally, two alternative process setups are proposed, which were both found viable

18 through a combination of experiments and simulations, and can be developed into full-scale

19 processes. The resulting two-step enzymatic biodiesel process - transesterification followed

20 by esterification - provides a potential process layout for the industrial production of

21 biodiesel.

22

23

Keywords.

24 Biodiesel, FAME, lipase, esterification, drying process, high yield, Candida antarctica lipase B 


\section{Introduction}

One of the most valuable tools in achieving sustainable chemical production is the use of enzyme-based process technology $[1,2]$. An excellent example is the enzymatic production of fatty acid methyl esters (FAME), commonly termed biodiesel [3]. For biodiesel production, the advantages of using enzymes are lowered operating temperatures and pressures, better quality of glycerol byproduct, and less waste, all of which reduce operating costs. In fact, the enzymatically-catalyzed biodiesel production process has already been commercialized and is currently in use in industry $[4,5]$. Today, a liquid lipase formulation (marketed by Novozymes as Eversa Transform 2.0) is a widely used biocatalyst for this particular application. It catalyzes the conversion of triglycerides, as well as free fatty acids (FFAs), with low waste generation and good profitability compared to the conventional alkalinecatalyzed process [6]. A particularly attractive feature of the enzymatic process is that it allows the use of cheap, low-quality feedstocks with minimal pretreatment, unlike the alternative chemical procedure [3]. Indeed, using this technology, economically viable processing of high FFA-containing feedstocks becomes possible.

However, even though the current enzymatic process results in a high yield of FAME on triglyceride, the product still contains 2-3 wt.\% FFA (regardless of the feedstock composition), since the reaction is equilibrium limited [7]. Today, FFA is removed by saponification, which is an expensive processing step and therefore should be avoided $[8,9]$. Tit is expensive mainly because of significant amounts of FAME lost in the saponification, handling of waste and water, as well as re-acidification for recycle of the soap stock.

It is well known that avoiding saponification is potentially achievable through enzymatic esterification of the remaining 2-3 wt.\% FFA (Scheme 1). Nevertheless, this reaction is reversible, meaning that to convert all the residual FFA to alkyl ester, the equilibrium needs to be driven by using either an excess of methanol, or else by removing water during the 
reaction. However, in practice only water can be removed, because an upper methanol concentration limit exists, above which the enzyme becomes unstable [10].

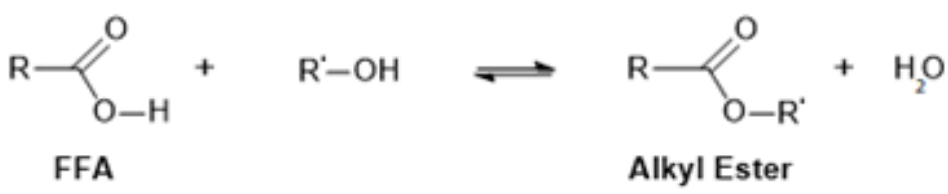

3

4 Scheme 1. Reversible esterification of FFA with an alcohol (typically methanol).

6 It is well known that lipases such as Candida antarctica lipase B (CALB) catalyze reactions at a liquid-liquid interface $[11,12]$. Furthermore, CALB shows relatively high activity and stability at very low water concentrations making it ideal for this case $[13,14]$. In this work we have investigated the idea of using glycerol as the main component of the reaction system to obtain a liquid-liquid interface and serve as a liquid enzyme carrier. Use of liquid enzyme has the added advantage of using a cheaper enzyme formulation as well as avoiding the need for filtration, when compared to immobilized enzyme formulations [15]. Additionally, the enzyme was found recoverable through simple decantation of the glycerol phase. One problem with using a liquid enzyme formulation is that it introduces some water with the enzyme, although this is mitigated by dry glycerol binding the water [16]. A similar study using another enzyme, Calera Trans $L(C T L)$, in a liquid-liquid system quite similar to this work, also confirms the difference in FFA at equilibrium between an immobilized enzyme and liquid enzyme formulation [17].

Despite the benefit, in the scientific literature there are few reports of this particular reaction [11], especially to achieve low residual FFA concentrations. Key to this is removal of water, which we have examined both using a stirred bubble reactor (SBR) [11], and alternatively flash columns [18]. A combination of process model simulations and experimental results have been used to show a first proof-of-concept and thereby substantiate that this can be a viable novel process. 


\section{2. Process principles}

\section{2.1. Theoretical effects of stepwise and continuous water removal}

4 Although the reaction of interest here uses a liquid formulation of CALB, the principle of

5 operation can be illustrated by a previously published model using immobilized CALB

6 (Novozym 435) for the esterification reaction [19]. A simulation of an esterification using this

7 model is shown in Figure 1. Here water is removed stepwise through an arbitrary drying

8 procedure (set at 15 minutes) to $250 \mathrm{ppm}$, after which methanol is again added to $4 \%$ (w/w).

9

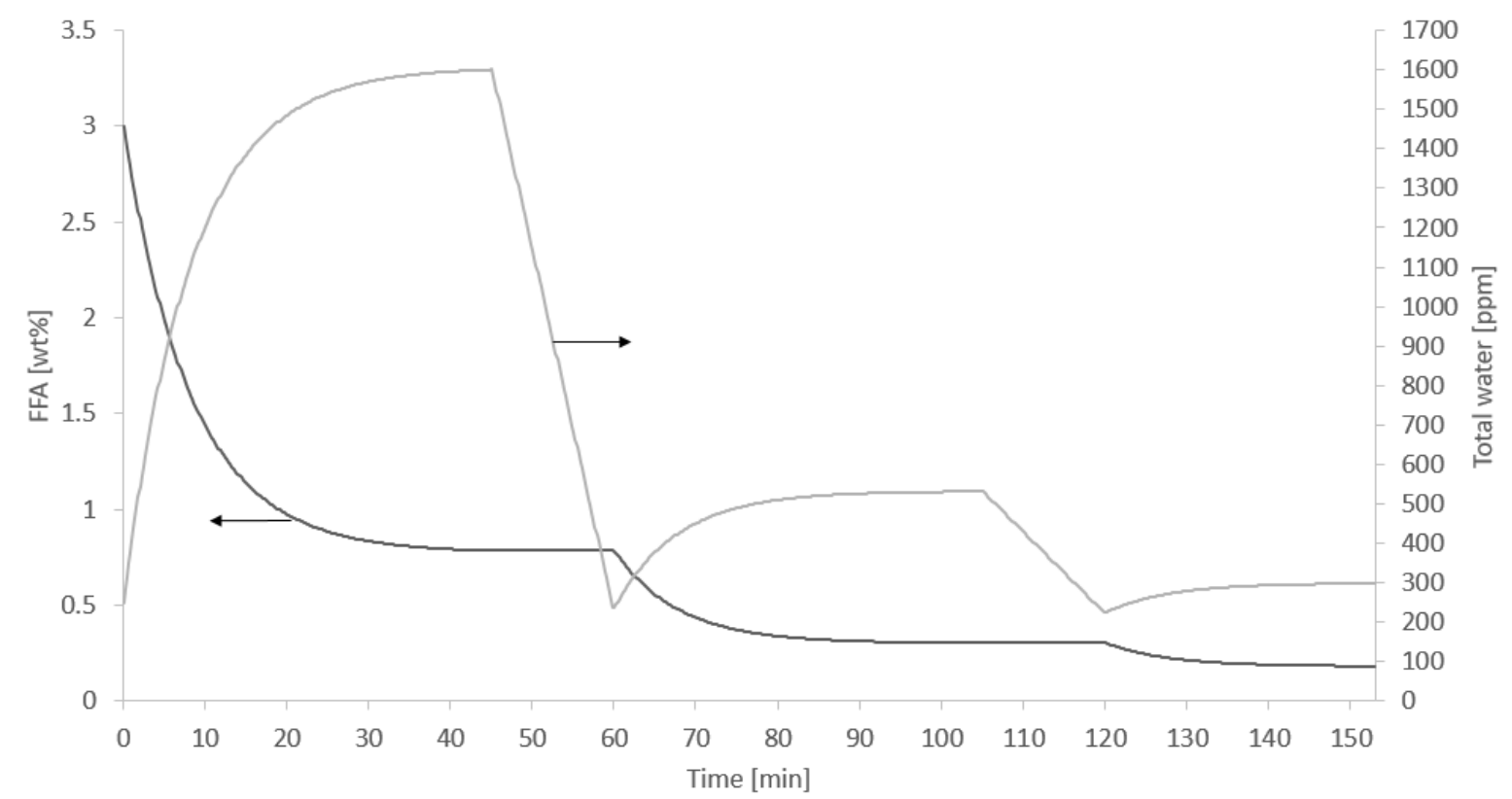

11 Figure 1. Model simulation of esterification using stepwise water removal. Reaction runs used $5 \%(w / v)$ Novozym 435. After drying $4 \%(w / w)$ methanol was added. The black line represents the simulated FFA concentration, and the grey line, the simulated water concentration [adapted from19].

According to the simulation shown in Figure 1, a stepwise repeated reaction-drying procedure for the esterification of FFA can achieve a residual FFA concentration of less than $0.25 \mathrm{wt} . \%$. Indeed, it is easy to conceive of such a process using several steps of reaction and drying using flash columns [18]. 
2 An alternative to stepwise removal of water could be continuous drying, where a continuous

3 shift in equilibrium towards complete FFA esterification is obtained. Using the same model,

4 whilst continuously removing (an arbitrarily chosen) $0.5 \%$ water per minute, gives the

5 simulation shown in Figure 2. The SBR process utilizes this principle.

6

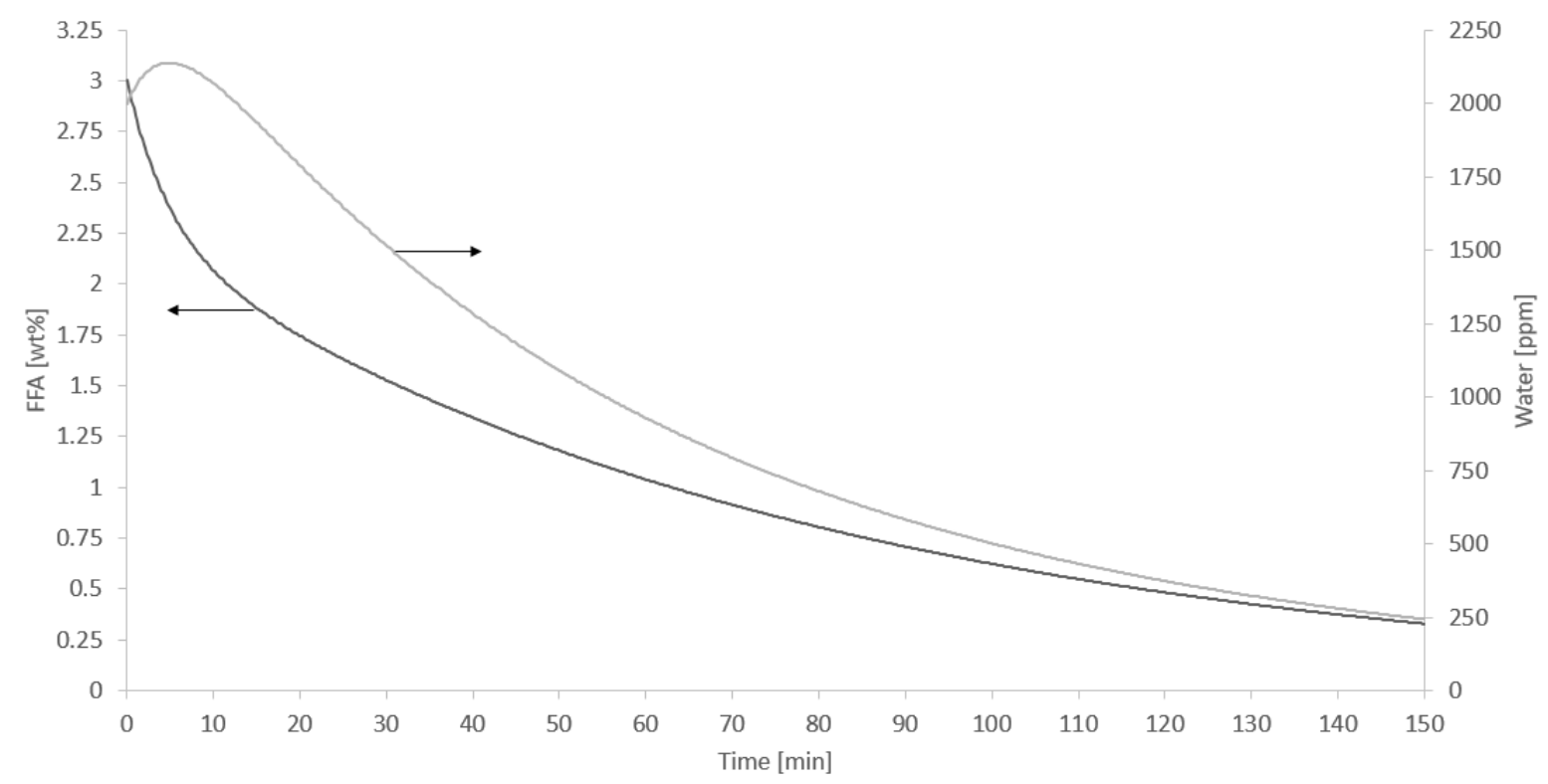

8 Figure 2. Continuous reaction and drying model simulation. The esterification was catalyzed

9 by $5 \%(\mathrm{w} / \mathrm{v})$ Novozym $435.2 \%(\mathrm{w} / \mathrm{w})$ methanol is always present. The black line represents 10 the simulated FFA concentration, and the grey line, the simulated water concentration.

\subsection{Stirred bubble reactor (SBR)}

13 The stirred bubble reactor (SBR) system uses a methanol-rich gas, bubbling through a

14 reaction vessel, in which the enzymatic esterification reaction is catalyzed. In the reaction

15 vessel, methanol transfers from the methanol-rich gas bubbles to the liquid. At the same

16 time, the reaction produces water as a by-product which is preferentially transferred into the

17 gas phase. The resulting gas phase leaves the reaction vessel and is bubbled through a

18 second vessel containing liquid methanol. In this vessel water is condensed and absorbed

19 by the liquid methanol. The relatively dry methanol-rich gas in the headspace of the 
1 methanol vessel is then circulated back to the reaction vessel. This results in a net transfer

2 of water from the reactor to the methanol vessel. A patent on a method similar to the SBR

3 examined here, was previously filed [20]. Figure 3 shows an overview of the process, where

4 the first vessel has been termed the 'reactor', and the second the 'condenser'.

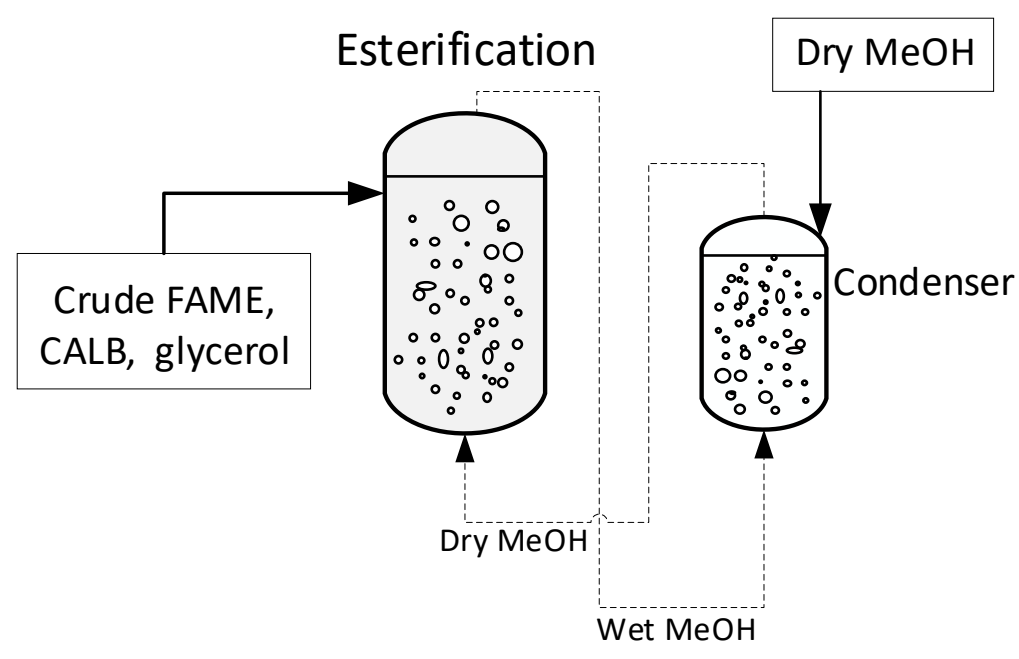

8 Figure 3. Overview of the stirred bubble reactor process. Left: Esterification reactor. Right:

9 (condenser) containing initially dry methanol. The dashed lines represent a dry methanol gas stream from the headspace of the condenser to the reactor, and wet methanol gas stream

11 from the reactor back to the condenser.

13 In order for the SBR process to work, two requirements must be met. First, the methanol

14 concentration needs to be maintained at a reasonable level in the reactor at steady-state.

15 Hence, while being high enough to favor the equilibrium towards FAME, it should not be at a concentration so high that it results in enzyme inactivation. Second, the driving force for the evaporation of water into the gas phase bubbling though the reactor should be adequate. Both are determined by the vapor-liquid equilibrium of methanol and water in the condenser and are correlated with the temperatures of the two liquids and the amount of methanol (compared to feedstock), in the condenser. This determines the driving force, and thereby

21 the rate of mass transfer, and hence final water and methanol concentrations. 


\section{3. Materials and methods}

\section{3.1. Materials}

4 Glycerol and methanol were of analytical grade with purity $>99.5 \%$. Glycerol had a water concentration of around 1000 ppm, methanol had a water concentration of around $200 \mathrm{ppm}$.

6 Oleic acid was of technical grade with purity $>90 \%$, with the remainder being mainly other

7 fatty acids. The enzyme used was a liquid formulation of CALB (containing 43.7 wt. \% water)

8 (NS88007, Novozymes A/S, Bagsvaerd, Denmark). FAME/Biodiesel (Acidity equivalent to $9 \sim 0.2$ wt. \% FFA) from palm oil with added oleic acid was used as feedstock.

11 Esterification reactions were carried out at three different scales. $30 \mathrm{~g}$ scale experiments were conducted in $150 \mathrm{~mL}$ square flasks (DURAN). $300 \mathrm{~g}$ scale experiments were conducted in centrifuge tubes (Polycarbonate, $500 \mathrm{~mL}, 69 \times 160$, Beckman Coulter Life Sciences). Both were run in a shaking incubator (New Brunswick Scientific ${ }^{\text {TM }}$ Innova ${ }^{\text {TM }} 44$ Incubator Shaker) at $250 \mathrm{rpm}$, maintained at $40^{\circ} \mathrm{C} .450 \mathrm{~g}$ scale experiments using the SBR system were conducted in a $1 \mathrm{~L}$ temperature-controlled glass reactor with a height of $14 \mathrm{~cm}$ and a diameter of $10 \mathrm{~cm}$, and mixed with a 4-vertical winged propeller at $500 \mathrm{rpm}$, and maintained at $40^{\circ} \mathrm{C}$. The condenser comprised a cylindrical vessel initially containing $500 \mathrm{~mL}$ of dry methanol. It was agitated with a 4-vertical winged propeller at $500 \mathrm{rpm}$, and maintained at $25^{\circ} \mathrm{C}$.

\subsection{Methods}

\subsubsection{Reaction initiation}

Prior to the reaction, mixtures of crude FAME, glycerol and methanol were preheated to $40^{\circ} \mathrm{C}$. Enzyme was then added to start the reaction $(\mathrm{t}=0)$. Reaction progression was monitored by regularly taking samples $(2 \mathrm{~mL})$, which were heated to $100^{\circ} \mathrm{C}$ for 10 minutes followed by 2 minutes of centrifugation to separate the two liquid phases. 


\section{$2 \quad 3.2 .2$. Analysis}

3 Samples were analyzed for acidity in the FAME phase using the AOCS method and

4 calculated as an oleic acid equivalent [21]. Methanol and glycerides were quantified using

5 the Medium Infrared System (Bruker Tensor II) supported by the Eurofins Quality Trait

6 Analysis (QTA) calibration service according to the AOCS specification [22]. Water content

7 was measured using Karl Fischer titration (831 KF Coulometer with 774 Oven Sample

8 Processor) and calculated through component mass balances.

\subsubsection{Full factorial design}

A full factorial design with three center points was carried out at the $30 \mathrm{~g}$ scale using single step reactions to equilibrium with two levels of each factor: $0.5-5 \%$ glycerol, $2-6 \%$ methanol and $0.3-0.8 \%$ enzyme (w/w of crude FAME). Results were used to show the impact of glycerol, methanol and enzyme concentrations on the equilibrium FFA concentration without water removal.

\subsubsection{SBR operation}

The circulating gas flowrate between the vessels was $0.4 \mathrm{~L} \mathrm{~min}^{-1}$ (or $0.8 \mathrm{vvm}$ (volume of gas per volume of reactor liquid per minute)).

Glycerol was added to a loading of $5 \%$ (w/w crude FAME). Methanol and enzyme loadings were varied and are given in \% (w/w crude FAME).

Development and simulation using an empirical mathematical model of the SBR system was implemented and conducted in MATLAB ${ }^{\circledR}$, using thermodynamic data obtained from literature [23, 24, 25].

\subsubsection{Thermal incubation study}

27 Thermal deactivation of enzyme was measured at $30 \mathrm{~g}$ scale. First a mixture of biodiesel without added oleic acid, $5 \%$ glycerol and $6 \%$ methanol (w/w of biodiesel) was pre-heated 
1 to the required temperature. Then $4.55 \%$ enzyme (w/w biodiesel) was added, and the

2 mixture incubated for 15 minutes. Following incubation, the mixture was rapidly cooled to

$340^{\circ} \mathrm{C}$. Then $10 \%$ oleic acid (w/w biodiesel) was added, and the esterification rate was

4 measured by sampling at 15 minute intervals for 1 hour while maintaining the mixture at

$5 \quad 40^{\circ} \mathrm{C}$. The excessive loading of enzyme and oleic acid were deliberately used to provide

6 rapid rate measurements.

7

\section{$8 \quad$ 3.2.6. Enzyme reuse study}

9 Centrifuge tubes were used as reactors, and the scale allowed for isolation of the glycerol 10 phase between batches through centrifugation at $1500 \mathrm{rpm}$ for 10 minutes and subsequent 11 manual decanting. After each batch, fresh preheated FAME and methanol were added, and 12 the subsequent esterification reaction mixture was sampled to allow measurement of the reaction rate.

14 The initial rates of reaction during the first 4 hours of each reaction were obtained through

15 linear regression of the first 3-5 measurements, until the $R^{2}$ value was beneath 0.95 . The equilibrium FFA concentration after 20 hours was measured for each batch.

\subsubsection{Flash VLLE simulations}

Flash column VLLE calculations were done computationally using the UNIFAC thermodynamic model in the steady state process simulation software Pro/II [26].

\section{Results and discussion}

\subsection{The effect of glycerol on equilibrium}

The effect of glycerol addition was studied in a full factorial experiment with three center points. Table 1 shows the linearized model obtained from the study. 


\begin{tabular}{|l|l|l|}
\hline Factor & Estimate & $\mathrm{p}$-value \\
\hline Intercept & 2.686 & $<0.0001$ \\
\hline Glycerol (0.5-5 [\%]) & -0.211 & 0.0016 \\
\hline Methanol (2-6 [\%]) & -0.153 & 0.0148 \\
\hline Enzyme (0.3-0.8 [\%]) & 1.239 & 0.0140 \\
\hline
\end{tabular}

2 Table 1. Estimated linear model parameters and their statistical significance for prediction of

3 equilibrium FFA in wt. \%. Loading ranges stated in \% (w/w of FAME). Initial FFA

4 concentration in the FAME was 2.9 wt. \%, with minimum FFA measured after reaction being

51.3 wt. \%. Total water concentrations range from $1700 \mathrm{ppm}$ at $0.3 \%$ (w/w of FAME) enzyme

6 to $3600 \mathrm{ppm}$ at $0.8 \%$ enzyme. Glycerol and methanol have negligible impact on the total

7 water concentration. Equilibrium was reached in 8-16 hours.

8

9 Comparing the effect of methanol and glycerol upon the equilibrium FFA concentration, shows the significance of glycerol. Glycerol is currently thought to impact the equilibrium through reduction in the apparent water concentration. Additionally, glycerol addition was found to be essential for the activity of the enzyme, which approached zero without glycerol present (data not shown). We attribute this to the formation of the liquid-liquid interface, upon which the enzyme acts, in the presence of glycerol. As expected, an increase in methanol loading resulted in higher conversion of FFA. For the enzyme dosage we found that the FFA content at equilibrium was higher at higher enzyme loading which we suggest is due to the additional water associated with using a higher enzyme concentration.

Whilst the presence of glycerol reduces the effect of water, it also shifts the equilibrium of the transesterification reaction towards formation of glycerides rather than FAME. We therefore 
1 examined this and found a slight increase in glyceride levels during a single step

2 esterification reaction (without drying) from $0.05 \mathrm{wt}$ \% $\%$ total glycerin in FAME to $0.25 \mathrm{wt}$. \% at 3 equilibrium in reactions run with a glycerol loading of $5 \%$ (w/w of FAME). This is the precise

4 glycerin limit according to biodiesel specifications (European Standard), but stems primarily

5 from the formation of monoglycerides, which increased from 0.24 to $0.61 \mathrm{wt}$ \%, and glycerol,

6 which increased from an immeasurably low value to 0.09 wt. \%. Both were measured using

7 the QTA method. However, the glycerol is reduced in subsequent downstream processing

8 like water washing, resulting in FAME within the biodiesel specification.

9

\section{4.2. Enzyme and glycerol reuse}

11 Having established a working liquid CALB enzyme system for esterification, we examined enzyme reusability. This is typically the primary benefit of immobilized enzymes, but our proposed liquid enzyme system has a similar advantage, since the enzyme is situated primarily at the phase interface between the two liquid phases. This enables isolation of most of the enzyme with the glycerol phase by decanting/centrifugation. Figure 4 shows the measured esterification rates on sequential batches of FAME. Rates were measured using the standard procedure in $300 \mathrm{~g}$ scale batches.

Some enzyme activity is lost as shown in Figure 4, but the majority is recovered. The total enzyme activity loss is around $15 \%$, meaning around $7.5 \%$ per batch. In summary, the results show excellent enzyme stability in use and the potential for reuse (translating to a low enzyme addition requirement per batch, when operating at steady state industrially). 


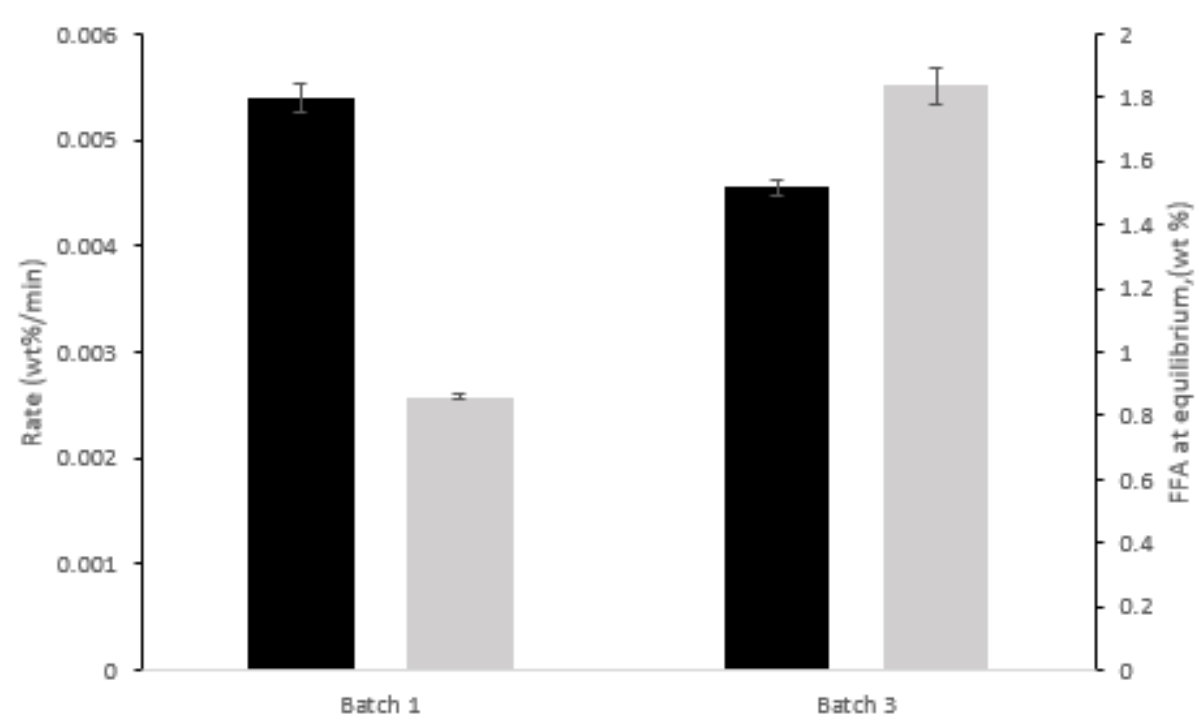

2 Figure 4. Initial reaction rates (black columns) and final equilibrium FFA concentrations

3 (grey column) in $300 \mathrm{~g}$ scale experiments. Initial mixture contained $3.2 \mathrm{wt} \%$ FFA with and

4 enzyme loading of $1 \%$ (w/w of FAME) and $5 \%$ added glycerol. In each batch of FAME

5 esterified, $6 \%$ methanol was added.

6

7 4.3. Stepwise flash/reaction process

8 Removal of water can be done through the well-established flashing operation, using the

9 difference in boiling points between water and FAME. A stepwise repeated reaction - flash

10 system would therefore allow the equilibrium to be shifted towards further conversion of FFA,

11 as the model simulation shows in Figure 1.

13 The results in Figure 5 show reactions at different initial FFA and water concentrations, and

14 the corresponding FFA conversions. The figure can be used to estimate the number of reaction-flash steps required. For example, a reaction starting with $3.6 \mathrm{wt}$. \% FFA reaches equilibrium at $0.9 \mathrm{wt}$ \% FFA, subsequent drying and a second reaction with fresh methanol would achieve an FFA concentration beneath $0.5 \mathrm{wt}$. \%. In fact, these reactions were conducted at elevated water concentrations relative to those obtainable through biodiesel flashing industrially. At industrial scale, water would be controlled by an additional flash prior to the reaction. Furthermore, in an industrial plant, less enzyme would be added (and hence 
1 less water) since glycerol (with enzyme) would likely be recycled. This means that in an

2 industrial plant even lower FFA concentrations can be expected, than those predicted from

3 Figure 5.

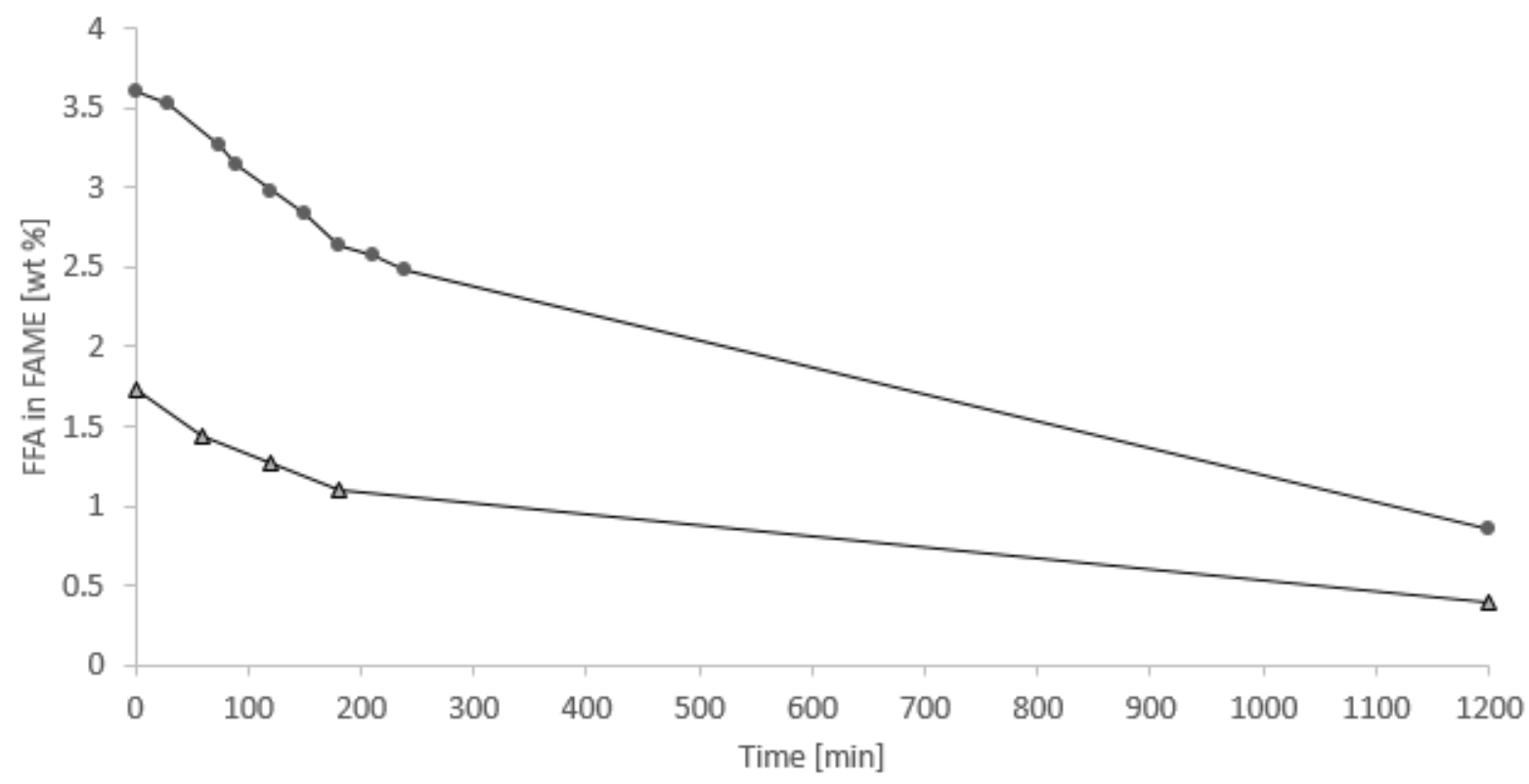

4

5 Figure 5. Reactions imitating first and second step reactions at high initial water

6 concentrations. Circles: $1 \%$ NS88007, $5 \%$ glycerol, $4 \%$ methanol, $300 \mathrm{~g} \mathrm{FAME}$, Initial

7 water $\approx 5500$ ppm. Triangles: $0.455 \%$ NS88007, $5 \%$ glycerol, $6 \%$ methanol, $30 \mathrm{~g} \mathrm{FAME,}$

8 Initial water $\approx 2000 \mathrm{ppm}$.

\subsection{CALB thermal stability in flash columns}

12 Through flash simulations, it was established that temperatures above $50^{\circ} \mathrm{C}$, along with

13 industrially feasible pressures of around 0.15 bar would be necessary to obtain effective

14 water removal. Additionally, a maximum of 15 minutes residence time was assumed necessary in the flash columns. To obtain the maximum allowable temperature with respect to enzyme stability, a thermal incubation study was conducted. As shown in Figure 6, CALB was found thermally stable, with no activity loss measured after 15 minutes at $55^{\circ} \mathrm{C}$. This set the maximum operating temperature for subsequent flash simulations. 


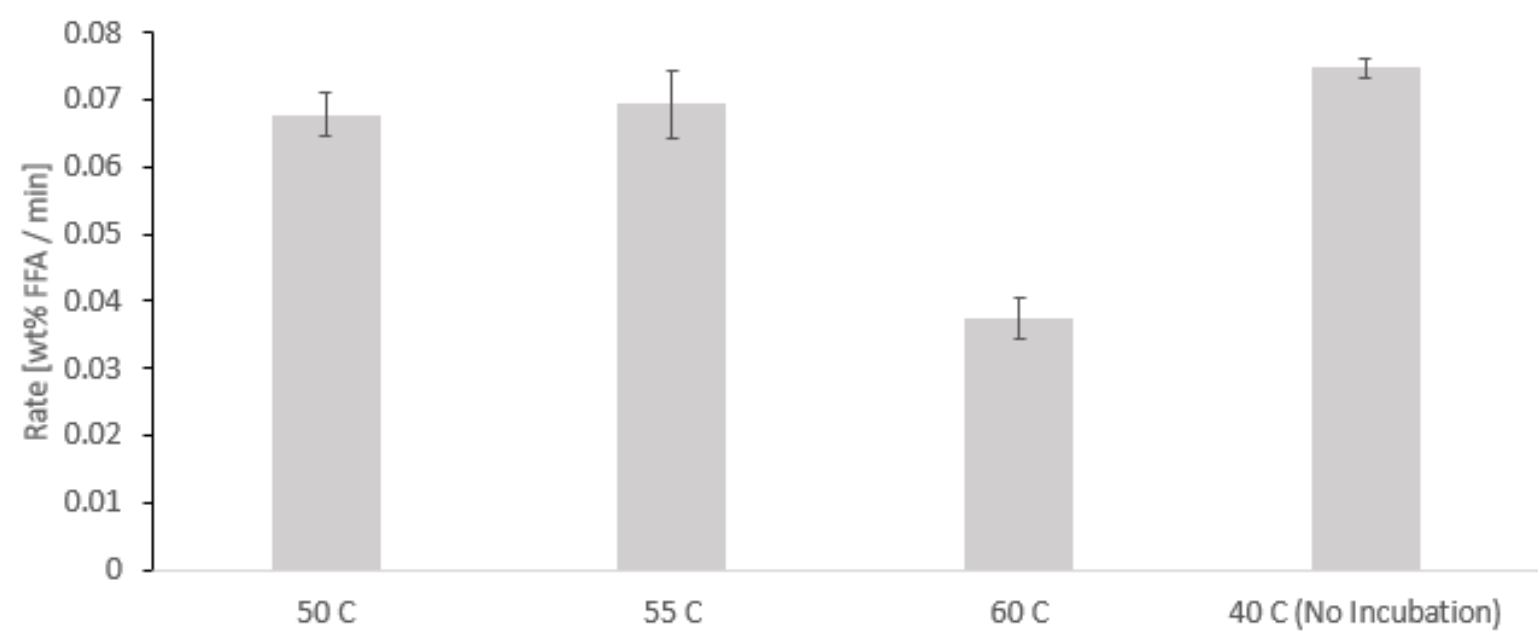

Figure 6. Thermal incubation study. $30 \mathrm{~g}$ scale reactions, 15 minutes incubation at indicated temperatures with $6 \%$ methanol, $5 \%$ glycerol, and $4.55 \%$ NS88007 (w/w of FAME). FFA to 10 wt. \% was added prior to rate measurements. Rate measured at $40^{\circ} \mathrm{C}$.

\subsection{Flash column simulations}

Utilization of the UNIFAC thermodynamic model for simulation of phase equilibria yielded flash column simulations [26]. A simple one-step flash column was simulated operating at an inlet temperature of $55^{\circ} \mathrm{C}$ and a pressure of 0.15 bar in the column, with an inlet feed consisting of $32.64 \%$ M-palmitate, 5.87 wt. \% M-stearate, 41.00 wt. \% M-oleate, 7.65 wt. \% M-linoleate, 4.49 wt. \% glycerol, 5.39 wt. \% methanol, 2.70 wt. \% FFA (oleic acid), and 2500 ppm water, simulating wet crude FAME (as if directly from the Eversa Transform transesterification reaction vessel) with addition of $5 \%$ glycerol and $6 \%$ methanol (w/w of crude FAME). This resulted in a water concentration of $963 \mathrm{ppm}$ in the liquid flash column outlet, but also reduced the methanol concentration to $2.28 \mathrm{wt}$. \%. More efficient water removal was obtained through a recycle loop around the flash column and heat exchanger, giving an equilibrium water concentration of 500 ppm when recycling $60 \%$ of the liquid outlet. This means the water concentration might be reduced significantly beneath that required to obtain in specification FAME (<0.25 wt. \% FFA), especially when considering the results of Figure 5, where 0.40 wt. \% FFA was measured after a reaction starting from 1.73 wt. \% FFA and around 2000 ppm water (calculated from mass balances). 


\section{4.6. Continuous SBR Process}

3 In a similar manner, as the above proposed stepwise flash process, the utilization of a stirred

4 bubble reactor has also been examined. Using an equal volume of methanol and FAME the

5 overall mass transfer coefficient $\left(\mathrm{K}_{\mathrm{L}} \mathrm{a}\right)$ of the system was estimated to be $0.60 \mathrm{~h}^{-1}$, assuming

6 the system would be able to remove all water present, without any reaction occurring.

7

8 Results from a proof-of-concept experiment are shown in Figure 7. As explained previously,

9 as a result of bubbling the reaction mixture with relatively dry methanol-rich gas, the FFA

10 concentration decreases. The methanol concentration stabilizes at a concentration of 2

11 wt. \% while the FFA concentration decreases over time. The reaction was concluded after 7

12 hours when the FFA concentration fell beneath 0.5 wt. \%.

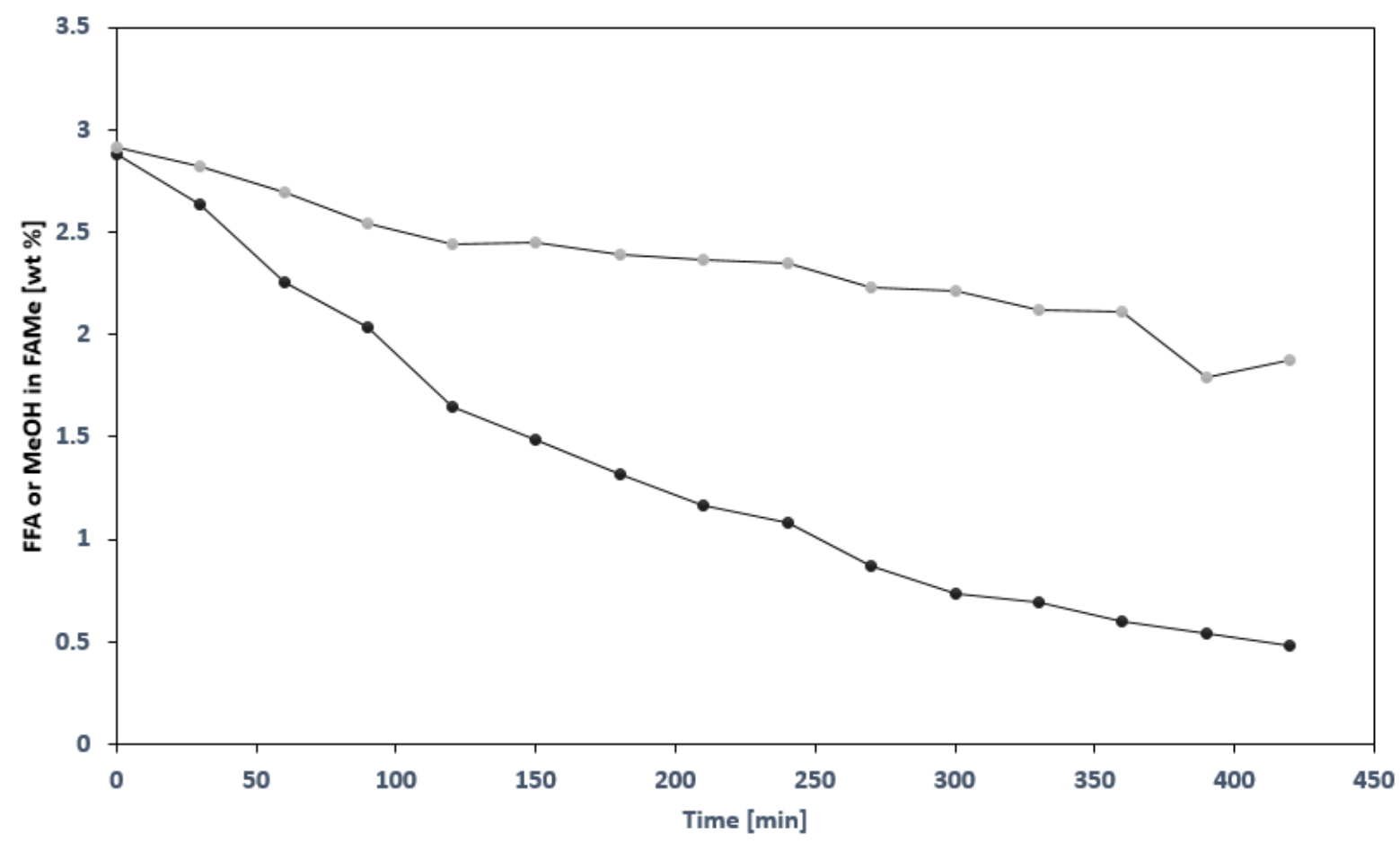

Figure 7. Simultaneous reaction and water removal using the SBR method. Light grey dots are representing methanol concentration [wt. \%] and black dots are representing FFA concentration [wt. \%]. Conducted using $450 \mathrm{~g} \mathrm{B100} \mathrm{Biodiesel} \mathrm{spiked} \mathrm{to} 3$ wt. \% FFA oleic acid, $4 \%$ (w/w of FAME and oleic acid) methanol, an equal volume of methanol 
corresponding to $500 \mathrm{~mL}$ in the condensing vessel and enzyme concentration of $0.455 \%$ (w/w of FAME and oleic acid) NS88007 with $5 \%$ (w/w of FAME and oleic acid) of glycerol.

These results confirm that the process should be able to ensure a final FFA concentration within the specification limits. The process relies on a range of parameters, which were then examined through modelling relating mass balances, partial pressures, gas flowrates and solubility characteristics. The model allows for calculation of the concentration change of water and methanol in both the esterification reactor and the condenser, while considering the temperature dependency of the relevant partial pressures. Equation (1) shows the balance over the esterification vessel of a component $i$.

$$
\frac{\mathrm{d} C_{R, i}(t)}{\mathrm{d} t}=\frac{Q_{g} \mathrm{M}_{i} \rho_{R}}{R V_{R}}\left(\frac{\pi_{C, i}}{T_{C}}-\frac{\pi_{R, i}}{T_{R}}\right) \quad\left[\frac{\mathrm{wt} \%}{\mathrm{~s}}\right]
$$

Where $C_{R, i}$ and $\pi_{j, i}$ are the mass concentration $\left[\mathrm{kg} / \mathrm{m}^{3}\right]$ and partial pressure $[\mathrm{Pa}]$ of component $i, T_{j}$ is the absolute temperature $[\mathrm{K}]$ in reactor or condenser. $Q_{g}$ is the volumetric gas flowrate $\left[\mathrm{kg} /\left(\mathrm{m}^{3} \mathrm{~s}\right)\right]$ and $M_{i}$ is the molar mass of component $i[\mathrm{~kg} / \mathrm{mol}]$. Using this as the basis, in the complete system there are two equations for each component, since a similar equation for the condenser can also be applied (with opposing signs for the driving force). The partial pressure of component $i$ is assumed to be related to the molar liquid fraction of the component. Using the modified and extended Raoult's law, the vapor pressure of a component in a mixture can be described as in equation (2):

$$
\pi_{i}=\gamma_{i} x_{i} p_{i}^{o}
$$

Where $x_{i}$ and $\gamma_{i}$ are the molar ratio and activity of component $i$, respectively, and $p^{o}{ }_{i}$ is the vapor pressure of the pure component, which is calculated by the Antoine equation. The thermodynamic activity of the different components was estimated using solubility 
1 parameters and molar volumes from the Wilson Equation for binary systems [23]. Relevant

2 physicochemical parameters for the modelling are shown in Table A1 in the appendix.

3

4 It should be noted that no binary interaction parameters describing the interaction in a

5 FAME-water system have been obtainable from scientific literature. Hence, water was

6 modelled as ideal in the reactor and it was assumed that only methanol and water would be

7 volatile, so no evaporation of FAME occurs. To simplify the model, terms for reaction and

8 mass transfer rates were excluded, meaning the model works on an arbitrary timescale.

9

10 Simulation of the SBR system was done in $\operatorname{MATLAB}^{\circledR}$. Simulations were run using a

11 methanol mass fraction of $0.2(\mathrm{w} / \mathrm{w})$ and an initial water concentration of $3000 \mathrm{ppm}$ while

12 varying the temperature difference between tanks. This resulted in the plot shown in Figure 138

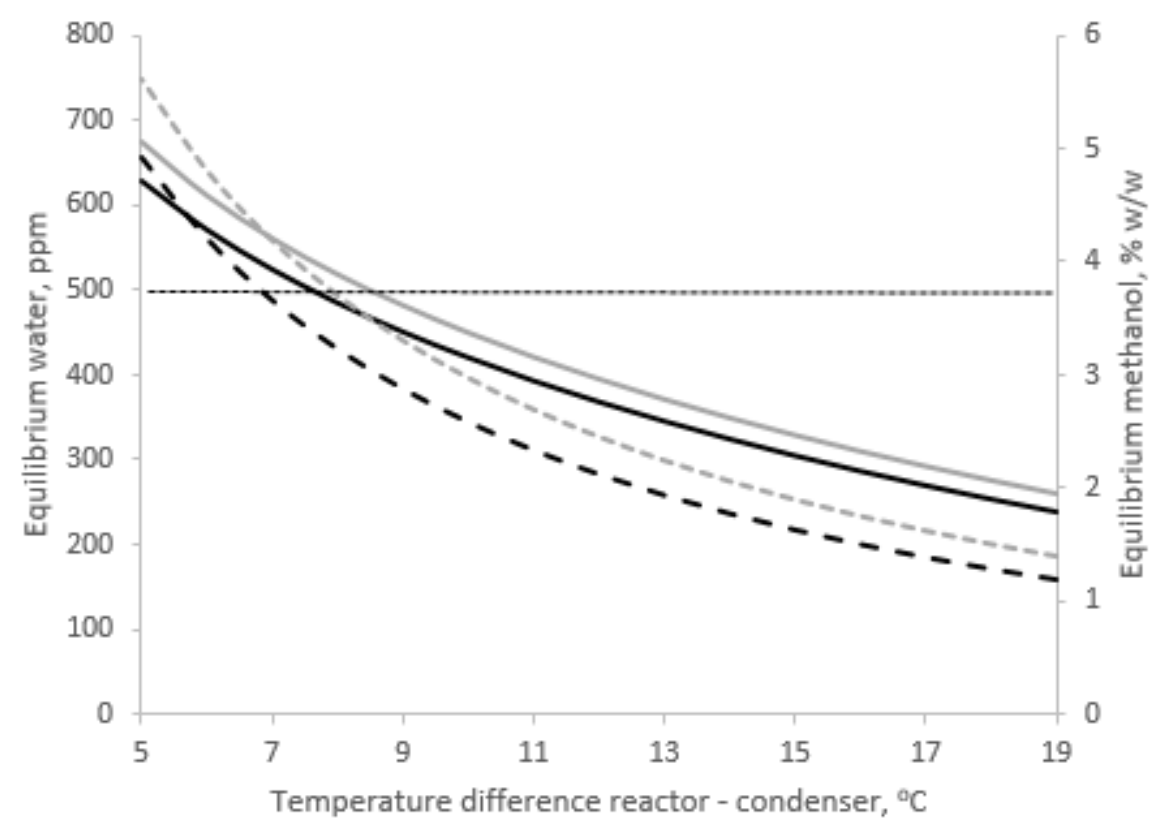

14

15 Figure 8. Simulation results on water (Solid lines) and methanol (Dashed lines) equilibria

16 when variating the condenser temperature at either a reactor temperature of 40 or $50^{\circ} \mathrm{C}$

17 (Light-grey and black lines, respectively) at a methanol mass fraction of $0.2(\mathrm{w} / \mathrm{w})$ and initial water concentration of $3000 \mathrm{ppm}$. 
2 Figure 8 shows that increasing the reactor temperature, $T_{R}$, from 40 to $50^{\circ} \mathrm{C}$ hardly

3 influences the attainable equilibrium. This suggests that increasing the reactor temperature

4 should only be done if a significant increase in enzymatic activity is observed. In contrast,

5 variation in the condenser temperature shows a larger effect. Indeed, keeping the

6 temperature difference small results in higher methanol and water concentrations and

7 therefore faster reaction rates, while increasing the temperature difference reduces the water

8 and methanol concentrations. At a temperature difference of $8^{\circ} \mathrm{C}$ (reactor at $40^{\circ} \mathrm{C}$ and

9 condenser at $\left.32^{\circ} \mathrm{C}\right)$ and a methanol mass fraction of $0.2(\mathrm{w} / \mathrm{w})$ it is estimated that the system

10 should be able to achieve a water concentration of 500 ppm from an initial concentration of

$113000 \mathrm{ppm}$. The rate of mass transfer will be governed by the volumetric gas flowrate and the

12 driving force (difference in vapor pressure).

14 Potentially, operating the system in an intermittent manner i.e. drying by bubbling for a

15 limited time, followed by reaction (throughout which water will accumulate) and subsequent

16 drying, might be one way to achieve a high driving force and reaction rate. A high driving

17 force could be maintained by a substantial temperature difference between the reactors,

18 while adding methanol in between gassing stages. The addition of methanol would be

19 required due the stripping of methanol from the reactor while at a high temperature

20 difference (Figure 8).

\section{5. Industrial implementation}

The results presented in this study indicate the viability of enzymatic esterification to reduce the FFA concentration to that required for in-specification biodiesel. For the first time this represents a wholly enzymatic solution for the commercial and sustainable production of biodiesel. In the following section we discuss the remaining issues for industrial

27 implementation.

\section{$28 \quad$ 5.1. Process Flowsheets}


1 Figures 9 and 10 are the proposed layouts for flash and SBR processes, respectively. Both

2 processes are shown here as an extension of the current Eversa Transform 2.0

3 transesterification, which has been documented previously and already commercialized.

4 Following the Eversa Transform transesterification, the heavy (aqueous enzyme-rich) phase

5 should be decanted prior to entering the subsequent esterification polishing process.

7

8 Figure 9. Stepwise esterification and flash process. Reactions are experimentally proven,

9 while the flash columns have only been simulated until now. This process can operate both

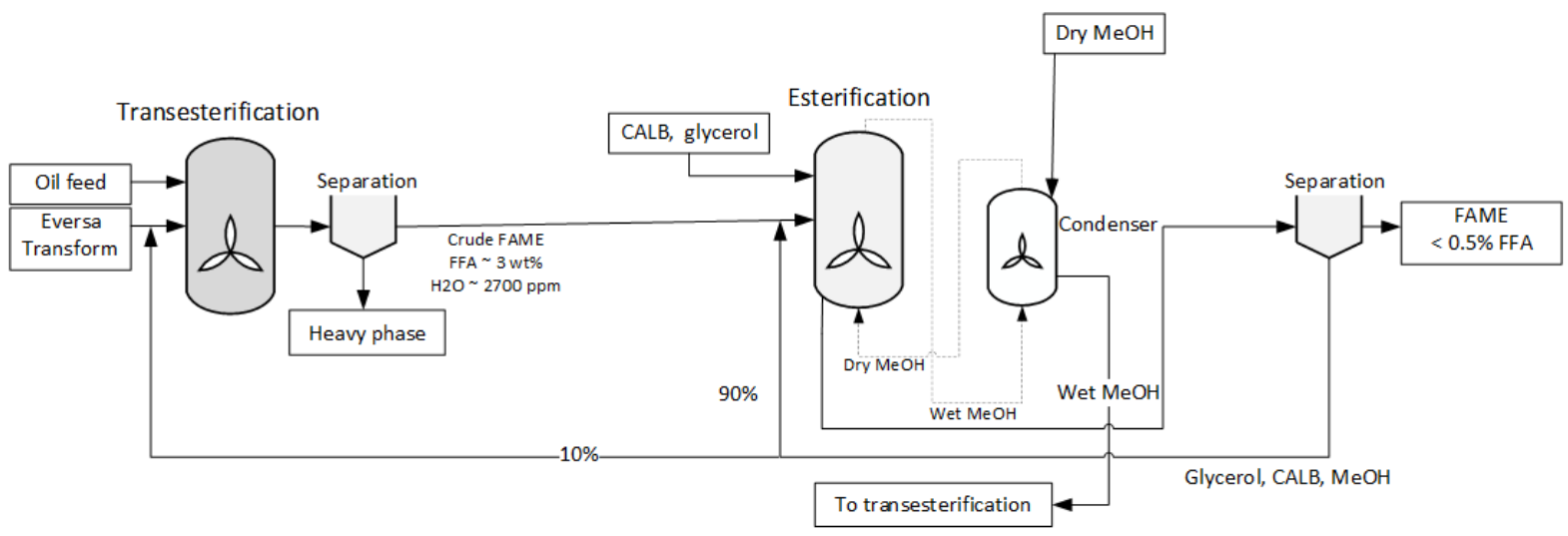

Figure 10. SBR process flowsheet. Currently only considered as a batch process.

The reaction results shown in Figure 5 (esterification with flash drying) suggest that only 2 esterification steps would be required, and with the flash column operation obtained from the UNIFAC model, a simple system for stepwise esterification and flashing could be designed as shown in Figure 9. After the Eversa Transform transesterification reaction, the water rich

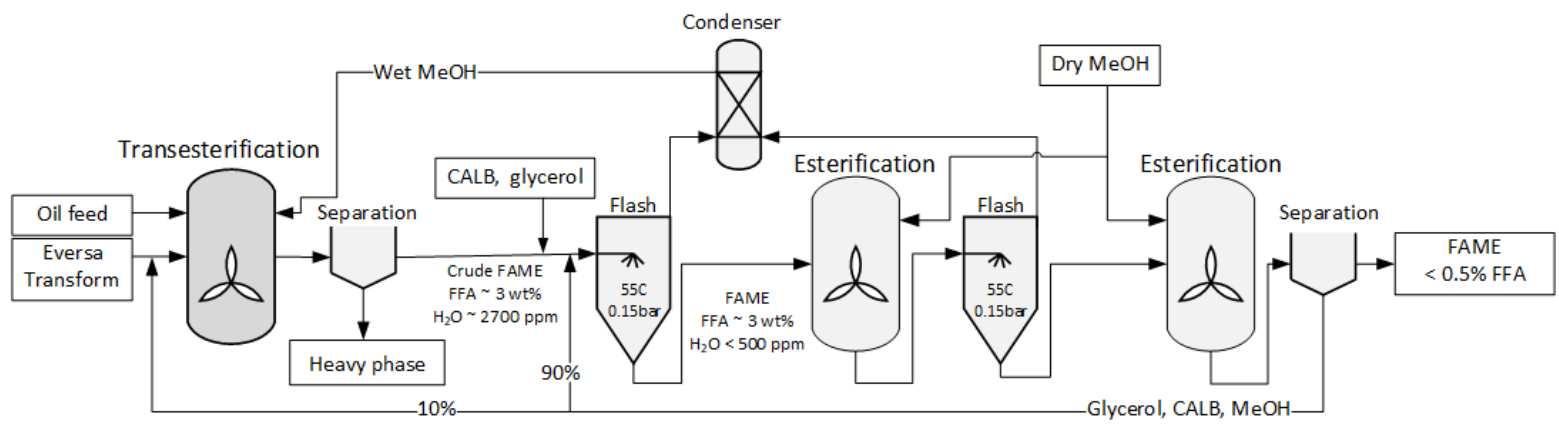


1 components should be mixed and flashed to reduce the water concentration prior to the

2 reaction. After the first reactor, residual FFA has been converted to FAME giving an

3 increased water concentration. A flashing step then removes a significant amount of this

4 water (and methanol), thereby shifting the equilibrium towards further FFA conversion in the

5 second reactor. Finally, a decanting step is used to recycle most of the enzyme and glycerol,

6 whilst removing a fraction through a purge in order to reduce the accumulation of undesired

7 byproducts. Additionally, methanol rich vapor from the flash columns and the purged

8 enzyme/glycerol phase are recyclable to the Eversa Transform reaction step. Experiments

9 (not shown) suggest 8-16 hours of reactor residence time per stepwise reaction would be necessary depending on whether continuous or batch reactors are used and dependent upon enzyme loading. Reactor volumes would then depend on the desired production capacity and the choice of operating mode. These times are commercially realistic and give viable reactor sizes (and of similar magnitude to those currently employed in industrial enzymatic biodiesel process (27)).

The simulated results shown in Figure 8 use a batch reaction using the SBR process, and on this basis a single batch would be sufficient for reduction of the FFA to beneath $0.5 \mathrm{wt}$. \%. With increased residence time and addition of dry methanol, the equilibrium might even be shifted within specification FFA concentrations. Figure 10 shows the proposed batch operating system, where the same recycling principles as in the stepwise flash system, have been used. Net reaction time will be shorter in this system, because batch operation is proposed.

\subsection{Benefits from reducing the size of the caustic wash}

Existing plants currently recycle soap stock stemming from the caustic wash. A significant portion of the FAME is trapped when separating the soap, thereby reducing overall productivity. The recycled soap is acidified (with sulphuric acid) to yield FFA. This also represents an added cost. Therefore, the proposed FFA esterification processes will not only 
1 increase the productivity, but also reduce or remove the need for caustic and sulphuric acid

2 additives, which also reduces waste.

3

\section{$4 \quad$ 5.3. Achieving a biodiesel product within specification}

5 An important point is the European specification on FFA concentration of 0.25 wt. \% (or 0.5 $\mathrm{mg} \mathrm{KOH/g} \mathrm{FAME).} \mathrm{The} \mathrm{proposed} \mathrm{SBR} \mathrm{process} \mathrm{has} \mathrm{been} \mathrm{shown} \mathrm{to} \mathrm{reach} \mathrm{the} \mathrm{specified} \mathrm{FFA}$ concentration, as previously described, while the flash process has not. The lowest FFA concentration reached in the flash process was around $0.40 \mathrm{wt} . \%$, which was reached at elevated water concentrations relative to that obtainable industrially (implying better results would be expected industrially). Therefore, a caustic wash might be necessary to reach the specified FFA concentrations with the flash process. Additionally, the caustic wash is also sometimes used for removal of sulphur compounds and other impurities, such as glycerides, and addition of caustic might therefore still be required (although much reduced), regardless of the FFA concentration.

\subsection{Reuse of enzyme}

Most of the enzyme activity was found recyclable by decanting the glycerol phase. This lowers enzyme cost, the amount of water added through liquid enzyme addition, and likewise reduces the costs associated with addition of dry glycerol. The experimental results shown in Figure 4 indicated a $7.5 \%$ activity loss per batch, suggesting that a $90 \%$ recycle should be possible. Reuse is thus a key part of the proposed processes, since the economics are highly dependent on it. It should be noted that the experiments conducted in this work have been carried out at an enzyme load of 0.455 wt. \% corresponding to an expected economically viable steady-state concentration, assuming five reuses.

\section{Future optimization}


1 Optimization of both processes is still possible and includes selection of temperature, $\mathrm{pH}$,

2 mixing, glycerol and methanol loadings as well as methanol addition regimes. The

3 experiments reported here were all run at $40^{\circ} \mathrm{C}$, but higher temperatures might also be

4 feasible. It is already known that the thermal stability of CALB is highly dependent on the

5 concentration of methanol, and this is a further area of optimization. Likewise, in other experiments (data not shown) different FAME qualities (ranging from biodiesel to crude

7 FAME stemming from sludge palm oil) have been examined. It was generally found that

8 higher FAME quality gave higher yield, indicating that the apparent equilibrium is influenced

9 by the FAME quality. It may also be that the acid titration method systematically results in overestimation of FFA concentration due to the presence of acidic byproducts in lower quality FAME. Finally, both processes are en-route to pilot scale testing.

\section{Concluding remarks}

We have presented a novel enzymatic FFA esterification reaction utilizing liquid CALB enzyme along with glycerol at low water concentrations. The system is capable of reducing FFA concentrations in crude biodiesel to levels close to, or within, specification. On this basis, we then proposed two comprehensive processes for the conversion of residual FFA in crude biodiesel stemming from the enzymatically-catalyzed biodiesel production (Eversa Transform transesterification). One system uses a stepwise reaction-flash. The other uses a stirred bubble reactor system, where dry methanol gas is bubbled through the FAME, thereby reducing the water concentration, yielding a continuous shift in equilibrium towards esterification of FFA. Both of the proposed processes have been found capable of significantly reducing waste generation and will reduce (or eliminate) the need for caustic washing. Soap recovery requirements will be lowered, and as a result, the productivity of existing and future biodiesel plants can be improved. Hopefully, this will result in a positive shift towards more sustainable biodiesel production. 
1 [1] R.A. Sheldon, J.M. Woodley, The role of biocatalysis in sustainable chemistry. 2018

2 Chem. Rev. 118: 801-834.

3 [2] M.V. Arbige, J.K. Shetty, G.K. Chotani, Industrial enzymology: The next chapter. 2019.

4 Trends Biotechnol. 37: 1355-1366.

5 [3] L. Fjerbaek, K.V.Christensen, B. Norddahl. A review of the current state of biodiesel

6 production using enzymatic transesterification. 2009 Biotechnol. Bioeng., 102: 1298-1315.

7 [4] A. Guldhe, B. Singh, T. Mutanda, K. Permaul, F. Bux. Advances in synthesis of biodiesel

8 via enzyme catalysis: Novel and sustainable approaches. 2015. Renew. Sustain. Energy

9 Rev., 41, 1447-1464.

10 [5] S. Hama, H. Noda, A. Kondo. How lipase technology contributes to evolution of biodiesel 11 production using multiple feedstocks. 2018 Curr. Opin. Biotechnol., 50: 57-64.

12 [6] J.H.C. Wancura, M.V. Tres, S.L. Jahn, J.V. de Oliveira. Lipases in liquid formulation for 13 biodiesel production: Current status and challenges. 2019 Biotechnol. Applied Biochem., 14 DOI: 10.1002/bab.1835.

15 [7] J.H.C. Wancura, V. Daniela, D.V. Rosset, M.A. Mazutti, G.A. Ugalde, J.V. de Oliveira, 16 M.V. Tres, S.L. Jahn. Improving the soluble lipase-catalyzed biodiesel production through a 17 two-step hydroesterification reaction system .2019 Appl. Microbiol. Biotechnol., 103: 7805187817.

19 [8] P.M. Nielsen, J. Brask, L. Fjerbaek, Enzymatic biodiesel production: technical and 20 economical considerations. 2008. Eur. J. Lipid Sci. Technol., 110: 692-700.

21 [9] L. Fjerbaek Sotoft, K.V. Christensen, B. Rong, B. Norddahl. Process simulation and 22 economical evaluation of enzymatic biodiesel production plant. 2010. Bioresource Technol., 23 14: 5266-5274.

24 [10] M. Lotti, J. Pleiss, F. Valero, P. Ferrer. Effects of methanol on lipases: molecular, kinetic and process issues in the production of biodiesel. 2015. Biotechnology Journal, 10: 22-30. 
1 [11] P.M. Nielsen, A. Rancke-Madsen, H.C Holm, R. Burton. Production of Biodiesel Using

2 Liquid Lipase Formulations. 2016. J. Am. Oil Chem. Soc., 93: 905-910.

3 [12] C.C. Gruber, J. Pleiss. Lipase B from Candida antarctica binds to hydrophobic

4 substrate-water interfaces via hydrophobic anchors surrounding the active site entrance.

$5 \quad$ 2012. J. Mol. Catal.B: Enzymatic, 84: 48-54.

6 [13] S. Dutta Banik, M. Nordblad, J.M. Woodley, G.H. Peters. A correlation between the 7 activity of Candida antarctica Lipase $B$ and differences in binding free energies of organic 8 solvent and substrate. 2016. ACS Catal., 6: 6350-6361.

9 [14] S. Dutta Banik, M. Nordblad, J.M. Woodley, G.H. Peters. Effect of water clustering on the activity of Candida antarctica Lipase B in organic medium. 2017. Catalysts, 7: 227.

[15] R. DiCosimo, J. McAuliffe, A.J. Poulose, G. Bohlmann. Industrial use of immobilized enzymes. 2013. Chem. Soc. Rev., 42: 6437-6474.

[16] C. Marcoli, T. Peter. Water activity in polyol/water systems: new unifac parameterization. 2005. Atmos. Chem. Phys., 5: 1545-1555.

[17] M.Y. Firdaus, Z. Guo, S.N. Fedosov. (2016) Development of kinetic model for biodiesel production using liquid lipase as a biocatalyst, esterification step. 2016 Biochem. Eng. J., 105: 52-61.

[18] C.A. Fleisher. Method for recovering unreacted alcohol from biodiesel product streams by flash purification. 2009. U.S. Patent No. 7,531,688.

[19] S.N. Fedosov, X. Xu. Enzymatic synthesis of biodiesel from fatty acids. Kinetics of the reaction measured by fluorescent response of Nile Red. 2011. Biochem. Eng. J., 56: 172183. 
1 [21] AOCS Ca 5a-40. (2017a). Free fatty acids in Crude and Refined Fats and Oils.

2 [22] AOCS Ck 2-09 (2017b) Determination of Various Properties of Biodiesel by the QTA 3 System Method.

4 [23] R.D. Felice, D. de Faveri, P. de Andreis, P. Ottonello, P. Component distribution

5 between light and heavy phases in biodiesel processes. 2008. Ind. Eng. Chem. Res., 47:

$6 \quad 7862-7867$.

7 [24] S. Kobuchi, K. Ishige, S. Yonezawa, K. Fukuchi, Y. Arai. Correlation of Vapor-Liquid

8 Equilibria for Polar Mixtures Using Wilson Equation with Parameters Estimated from

9 Solubility Parameters and Molar Volumes. 2011. J. Chem. Engng. Japan, 44: 449-454.

10 [25] Dortmund Databank. 2019.

11 http://ddbonline.ddbst.com/AntoineCalculation/AntoineCalculationCGI.exe?component=Meth

12 anol

13 [26] A. Fredenslund, R.L. Jones, J.M. Prausnitz. Group-contribution estimation of activity 14 coefficients in nonideal liquid mixtures. 1975. AIChE J., 21: 1086-1099.

15 [27] J. Price, M. Nordblad, H. Martel, B. Chrabas, H. Wang, P. Nielsen, J. M. Woodley, 16 Scale-up of industrial biodiesel production to $40 \mathrm{m3}$ using a liquid lipase formulation. 2016.

17 Biotechno. Bioeng., 113: 1719-1728.

18

19

20 


\section{$1 \quad$ Appendix}

2 Table A1: Physical and Chemical Data used for modelling of SBR.

\begin{tabular}{|l|l|l|l|l|}
\hline & Value & Unit & & \\
\hline Density Reaction (FAME) & 900 & $\mathrm{~kg} / \mathrm{m}^{\wedge} 3$ & \\
\cline { 1 - 3 } Density condenser (MeOH) & 791 & $\mathrm{~kg} / \mathrm{m}^{\wedge} 3$ & \\
\hline Water molar mass & 18.02 & $\mathrm{~g} / \mathrm{mol}$ & \\
\hline Methanol molar mass & 32.04 & $\mathrm{~g} / \mathrm{mol}$ & \\
\hline FAME molar mass & 269 & $\mathrm{~g} / \mathrm{mol}$ \\
\hline Universal gas constant & 8.31447 & $\mathrm{~J} /\left(\mathrm{mol}{ }^{*} \mathrm{~K}\right)$ & \\
\hline & & & \\
\hline
\end{tabular}

Physical properties of pure substances (Kobuchi et al., 2011)

\begin{tabular}{|l|l|l|l|l|}
\hline & Water & Methanol & FAME & Unit \\
\hline Molar volume at $25^{\circ} \mathrm{C}$ & 18.01 & 40.7 & & {$[\mathrm{~cm} 3 \cdot \mathrm{mol}-1]$} \\
\hline Molar volume at tb & 18.08 & 42.08 & & {$[\mathrm{~cm} 3 \cdot \mathrm{mol}-1]$} \\
\hline Solubility at $25^{\circ} \mathrm{C}$ & 47.9 & 28.2 & & {$\left[(\mathrm{~J} \cdot \mathrm{cm}-3)^{\wedge} 0.5\right]$} \\
\hline Normal boiling point & 100.001 & 64.511 & & {$\left[{ }^{\circ} \mathrm{C}\right]$} \\
\hline
\end{tabular}

Constants of Antoine's equation (Dortmund 2019)

\begin{tabular}{|l|l|l|l|}
\hline A & 807.131 & 8.0897 & \\
\cline { 1 - 3 } B & 1730.63 & 1582.27 & \\
\cline { 1 - 3 } & 233.426 & 239.07 & \\
\hline
\end{tabular}


Binary interaction parameters (Kobuchi et al. 2011)

\begin{tabular}{|l|l|l|l|l|}
\hline$\varepsilon(\mathrm{i}, \mathrm{j})$ & 0.0959 & 0.1512 & \multicolumn{2}{|l|}{} \\
\hline \multicolumn{4}{|l|}{ Interaction energy parameters (Felice et al. 2008) } \\
\hline$\lambda(\mathrm{i}, \mathrm{j})$ & 5550 & 3338 & {$[\mathrm{~J} \cdot \mathrm{mol}-1]$} \\
\hline
\end{tabular}

1

2 Latex Code for equations

3 Model:

$4 \quad$ begin equation\}

$5 \quad I d v\left\{C \_\{R, i\}(t)\right\}\{t\}=\mid \operatorname{frac}\left\{Q \_g \backslash \mid \operatorname{text}\{M\} \_\{i\} \backslash \backslash \operatorname{rho} \_R\right\}\left\{R \backslash V \_R\right\} \backslash \operatorname{Veft}\left(\backslash \operatorname{frac}\left\{\mid p i \_\{C, i\}\right\}\left\{T \_C\right\}-\right.$

$6 \backslash$ frac $\left.\left\{\mid p i \_\{R, i\}\right\}\left\{T \_R\right\} \backslash \operatorname{right}\right) \backslash \backslash$ quad $\operatorname{Veft}[\operatorname{lfrac}\{\mid \operatorname{text}\{w t\} \backslash \%\}\{\mid \operatorname{text}\{s\}\} \backslash \operatorname{right}]$

7 lend equation\}

8

9 Extended Raoult's Law:

10 begin $\{$ equation\}

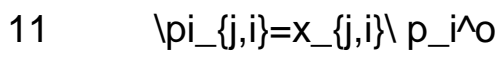

12 lend\{equation\}

13 